\title{
Youth Health Services, Development Programs, and Teenage Birth Rates in 55 California Cities
}

\author{
Mike Males \\ University of California, Santa Cruz
}

\begin{abstract}
Many advocacy groups depict sexuality education, abstinence education, health services, and development services to teenagers as pivotal factors in their birth rates. Data from California's 55 largest cities for 1990-2002 allow regression analyses of the associations between levels of health and development services to youth, socioeconomic factors such as poverty, and environmental factors such adult birth rates on rates of and changes in births to teenage mothers. The analysis found teenage birth rates vary 30-fold from California's richest to poorest city. Socioeconomic and environmental factors, chiefly adult birth rates and youth poverty rates, are associated with nearly $90 \%$ of the variance in teen birth rates. Contrary to assertions by many advocates, lower-income teens have greater access to health, sexuality education, and development services, and the availability of these services is not associated with lower rates of or greater reductions over time in teenage birth rates.
\end{abstract}

(c) 2006 Californian Journal of Health Promotion. All rights reserved.

Keywords: teen, sexuality, programs, poverty

\section{Introduction}

Considerable controversy surrounds the factors underlying the higher rates of birth among American teenage mothers of poorer socioeconomic classes compared to more affluent populations. High birth rates among populations suffering high rates of poverty are the chief reason U.S. teen birth rates exceed those of similarly affluent Western nations by a wide margin (Darroch et al., 2001).

Some observers take a socioeconomic view: that poorer young women have higher birth rates because of the conditions imposed by poverty itself, including the lack of financial assets necessary to pursue higher education and career options (Musick, 1993), extended-family structures that provides more caregivers for children of poorer young mothers (Luker, 1996), and economic advantages to poorer women of having children earlier in life (Hotz et al., 1997, 2000). In this view, teen mothers' birth rates are a function of social inequality and are directly related to the sexual behaviors of adults of similar socioeconomic status.
However, the predominant view expressed by major American teen-pregnancy prevention groups might be called "programmatic:" that is, teenagers' sexual behaviors constitute a "social problem" defined by their young age and can be treated separately from those of adults, and high teen birth rates result largely from poorer youths' lack of access to abstinence and sexuality education, contraceptive services, and youth development programs. For example, the California Adolescent Health Collaborative (2005) acknowledges that, "teen births are more prevalent among populations of lower socioeconomic status," but none of its policy recommendations include measures to reduce poverty among youths. Instead, CAHC's "strategies to reduce teen pregnancy and STIs [sexually transmitted infections]" are: "Provide teens with the information, skills, and support they need to practice safe sexual behavior, including abstinence... increase access to reproductive health care... increase the role males play in preventing adolescent pregnancy... decrease glamorization of irresponsible sexual behavior in the media." 
Similarly, Advocates for Youth (2005) concedes that, "most teenage mothers come from socially and/or economically disadvantaged backgrounds," but credits only "easy access to sexual health information and services" as the cause of "better sexual health outcomes" in European nations. The Sexuality Information and Education Council of the United States (2005) cites coming from "low-income families" as only one in a lengthy list of risks leading to higher odds of giving birth as teens. SIECUS states: "Young people who become infected with HIV, contract a STD, or face an unintended pregnancy often lack opportunities to receive accurate information and build critical skills," leading to its recommendation for "youth development programs" that include "sexuality and sexual/reproductive health education components that prepare young people to lead sexually healthy lives.”

Likewise, the Public Health Institute and the California Wellness Foundation note that "one of the best predictors of teen birth rates are poverty rates," neither advocates any measures to reduce adolescent poverty. Instead, PHI credits only "state funded reproductive health... and teen pregnancy prevention programs" and "program and policy grant initiatives funded by philanthropic foundations in California, led by the California Wellness Foundation" as "the solution" for reducing births by teenage mothers (Constantine \& Nevarez, 2002, pp. 5, 7). Wellness itself emphasizes "grants to outreach activities for reproductive health care; access to contraceptive services; and comprehensive programs for pregnant teens," emphasizing "peer-provider clinics and other reproductive health organizations that work with high-risk, sexually active, underserved teen populations" (California Wellness Foundation, 2005).

Even those, such as the Alan Guttmacher Institute, that cite a combination of socioeconomic and programmatic factors in research papers (Darroch et al., 2001) typically recommend only programmatic solutions: "Societal assistance to teenagers in their transition to adulthood, combined with acceptance of teenage sexual relationships, clear expectations for responsible sexual behavior and access to sexual and reproductive health services leads to lower rates of teenage pregnancy" (Alan Guttmacher Institute, 2001, press release). The National Campaign to Prevent Teen Pregnancy's (2005) prevention initiative, called "Putting What Works to Work," advocates a variety of education, service, and program initiatives. California's Get Real! About Teen Pregnancy (2005, campaign materials) urges adults to "recognize the need to encourage healthy behaviors and activities for teens as a way to help reduce unplanned pregnancies.”

Given the hundreds of studies now available, individual findings favorable to one point of view can be selected to show any effect, but only one intensive program, the National Adolescent Sexuality Training Center at The Children's Aid Society (2005), has consistently produced positive results. However, taken as a whole, the large body of research on the effectiveness of various sexuality, abstinence, and contraceptive education and programs in reducing births to teen mothers has been inconsistent and inconclusive (see reviews by Kirby, 2001, 2002). Even the studies that find significant results typically suffer from flaws in method such as selection biases between test and control groups, low sample retention, lack of replication of results for programs found effective in single studies, and failure to explain why similar programs have not shown similar results in other communities or time periods.

Nevertheless, a number of groups claim programmatic approaches can be credited with the low rates of teen births in European countries, variations in teen birth rates in certain American cities, and the large decline in teen births in the United States from 1991 to 2003. For example, in September 2004, Los Angeles's Get Real! and the San Francisco Bay Area's CAHC (2004) issued a "Reality Check" report ranking California's 55 largest cities (all those with populations of more than 100,000) in providing services to teens and in preventing teen births. The report rated Berkeley as "California's most teenager-healthy city" for providing teens with the greatest access to health and prevention services, including "a health center that readily hands out advice and 
condoms" to youths, credited with producing "the state's lowest birth rate among teen mothers" (Bender, 2004, p B1). In "Berkeley High: A Sex Ed Success Story,” Planned Parenthood also argues that Berkeley's "comprehensive sex education programs that are proven to work" (as opposed to abstinence education) and "web of support" has resulted in the fact that "for eight years running, Berkeley has had the lowest teen pregnancy rate in the state” (Lambert, 2005).

A factual problem with Get Real!, CAHC, and Planned Parenthood's statements is that California Center for Health Statistics' (2004) natality reports for 2002 and the Bureau of the Census' (2005) census of population by age for 2000 show that Berkeley does not rank lowest, but fifth, from the lowest, in teen birth rates among California's cities of more than 100,000 population. In fact, Berkeley has a higher teen birth rate (16.2 births by mothers under age 20 per 1,000 females ages 15-19) than three cities ranked as among the worst in youth services (Irvine, Glendale, and Santa Clarita). In particular, the city with the state's lowest teen birth rate, Irvine (3.3 per 1,000), ranks second worst in services to youth and teaches a "family life" curriculum stressing conservative, "universal moral values," anchored by such films as, "Why Abstinence? The Price Tag of Casual Sex" (Irvine Public Schools, 2003). If only programmatic approaches are compared and other factors are ignored, the opposite conclusion could be argued from Get Real!'s "Reality Check" data: that teaching abstinence from sex rather than providing teens with services produces lower teen birth rates.

While the National Campaign and other groups involved in the teen sexuality debate advocate expanded investment in education curricula and programmatic measures, none that I can find proposes redistributive policies, such as stronger social insurance programs to boost incomes of low income families, as a strategy to reduce teen birth rates. The question of whether educational and programmatic strategies can significantly reduce births by teenagers in the absence of significant, economic reforms is an important public policy question, especially given weak and diminishing efforts by authorities in the United States to reduce high rates of poverty among youth. If only major social investments to reduce the high rates of poverty suffered by American youth will bring down the birth rate among teens in the long term, over promotion of educational and program solutions as the answer to teen pregnancy inadvertently gives policy makers an easy way to avoid politically difficult economic reforms to reduce the poverty and related disadvantages that contribute to poorer teens' higher birth levels. This paper proposes to examine these issues on a multi-city basis by correlating variations in teen births rates with variations in the availability of health and development programs, teenage poverty rates and other economic variables, and adult birth rates in California's 55 largest cities.

\section{Data and Methods}

Births by age of mother, city, and year are extracted from the Birth Public Use file, an electronic data file available for 1990 through 2002 as of this writing from the California Center for Health Statistics (2004), Department of Health Services. Populations by sex and age for each of California's 55 largest cities (all of those with populations of 100,000 or more in 2000), as well as racial and Latino ethnic composition, poverty rates, population size, labor force participation, educational attainment, income, marital status, and home ownership are taken from the Bureau of the Census (2005). These show that in 2002, California's 55 largest cities had a total of 1.1 million teen women ages 10-19 who had 27,400 live births, and 3.1 million adult women ages 20-44 who had 247,300 live births. Adult birth rates are calculated for each city as a measure of background norms for childbearing and to provide a control variable against which to assess levels of and changes in teenage birth rates (Appendix A).

Rankings of each city according to its level of programs, services and opportunities for youth are taken from Get Real's and the California Adolescent Health Collaborative's (2004) "Reality Check" report. The report evaluated "six variables covering access to health services and seven youth development opportunity 
variables." The health services variables included the number of clinics and health centers (both those receiving and not receiving Title $\mathrm{X}$ funding), school based clinics and health centers, family PACT (Planning, Access, Care and Treatment, a federally subsidized family planning program) providers, pharmacies providing emergency contraception, and additional "health and well being services for teens." The youth development opportunity variables included scorings of youth involvement in decision making at the city and school district levels and the presence of Boys' and Girls' Clubs, YMCAs and YWCAs, mentoring programs, and federally- and statefunded after-school programs. Each city's services were assigned a quartile score of 1 (lowest 25\%), 2 (26\%-50\%), 3 (51\%-75\%) or 4 (highest 25\%) on each of the variables. The scores were summed, and each city was assigned rankings for health services, development programs, and total score (Appendix A).

Several correlation and regression analyses were conducted to assess the associations of each city's rate of births among teen mothers with other relevant variables, including poverty, adult birth rates, and the indexes of youth health services and development opportunities. The statistical significance threshold used here, $\mathrm{p}<$ 0.01 , is more stringent than that used in most analyses (0.05).

\section{Results}

\section{Levels of Teen Birth Rates}

California's 55 largest cities show immense variation in rates of births by teenage mothers. The highest rate (108.9 births by mothers under age 20 per 1,000 females ages 15-19) in 2002, found in Bakersfield, is more than 30 times higher than the lowest (3.3, in Irvine). The variation in teen birth rates is considerably more extreme than the variation in adult birth rates, which ranges four-fold from highest (134.6 per 1,000 females ages 20-44, also in Bakersfield) to lowest (35.8, in Berkeley) (see Appendix A).

As these congruencies suggest, the rate of births by teens is strongly correlated with the rate of births by adults, and youth poverty rates are strongly correlated both with rates of births by teenage mothers and by adult mothers. The strongest correlation was between youth poverty rates and the net teen birth rate, that is, the ratio of the teen birth rate to the adult birth rate. The adult birth rate is associated with $75 \%$ of the variation in teen birth rates across the 55 cities; together, the adult birth rate and the youth poverty rate are associated with $89 \%$ of the variation in teen birth rates.

Teen birth rates are strongly correlated with the same economic circumstances that affect adult birth rates such as poverty rates, household income, educational attainment, and labor force participation (Table 1).

Table 1

Correlation between teen birth rate and selected variables, California’s 55 largest cities, 2002

\begin{tabular}{|c|l|l|l|}
\hline & \multicolumn{1}{|c|}{$\begin{array}{c}\text { Teen } \\
\text { Birth Rate }\end{array}$} & $\begin{array}{c}\text { Adult } \\
\text { Birth Rate }\end{array}$ & $\begin{array}{c}\text { Net Teen } \\
\text { Birth Rate }\end{array}$ \\
\hline Birth rate characteristics & & & \\
\hline Teen (age 10-19) birth rate & 1. & $0.868^{* *}$ & $0.895^{* *}$ \\
\hline Adult (age 20-44) birth rate & $0.868^{* *}$ & 1. & $0.619^{* *}$ \\
\hline Net teen (teen vs. adult) birth rate & $0.895^{* *}$ & $0.618^{* *}$ & 1. \\
\hline Services for teens & & & \\
\hline Health services for teens & $0.360^{*}$ & 0.191 & $0.479^{* *}$ \\
\hline Youth development services & 0.271 & 0.088 & $0.429^{*}$ \\
\hline Total services & 0.340 & 0.149 & $0.491^{* *}$ \\
\hline
\end{tabular}




\begin{tabular}{|l|l|l|l|}
\hline & $\begin{array}{c}\text { Teen } \\
\text { Birth Rate }\end{array}$ & $\begin{array}{c}\text { Adult } \\
\text { Birth Rate }\end{array}$ & $\begin{array}{c}\text { Net Teen } \\
\text { Birth Rate }\end{array}$ \\
\hline City characteristics & & & \\
\hline City population size & 0.129 & -0.001 & 0.253 \\
\hline Teen poverty rate & $0.775^{* *}$ & $0.536^{* *}$ & $0.793^{* *}$ \\
\hline Median household income & $-0.744^{* *}$ & $-0.530^{* *}$ & $-0.782^{* *}$ \\
\hline Percent owning own home & -0.257 & -0.026 & $-0.456^{* *}$ \\
\hline Percent with high school education & $-0.718^{* *}$ & $-0.538^{* *}$ & $-0.733^{* *}$ \\
\hline Percent with bachelor's degree & $-0.668^{* *}$ & $-0.613^{* *}$ & $-0.573^{* *}$ \\
\hline Percent married & -0.235 & 0.043 & $-0.472^{* *}$ \\
\hline Percent in labor force & $-0.666^{* *}$ & $-0.554^{* *}$ & $-0.632^{* *}$ \\
\hline
\end{tabular}

${ }^{*} \mathrm{p}<.01 ;{ }^{* *} \mathrm{p}<.001$

Table 2 illustrates when compared to cities with the lowest (under 10\%) rates of youth poverty, cities with the highest youth poverty rates (over $30 \%$ ) have teen birth rates averaging 3.7 times higher, including rates twice as high for blacks and Latinos, three times higher for whites, and eight times higher for Asians. Further, teen birth rates rise sharply — much faster than do adult birth rates - with poorer economic circumstances. In cities in which youth poverty rates exceed $30 \%$, the teen birth rate is fourfifths of the adult birth rate, compared to just one-third of the adult birth rate in cities in which fewer than $10 \%$ of youth live in poverty.

Since the economic variables are highly intercorrelated and can stand in for each other, substitution of another variable (such as median household income) for youth poverty affects the equation only modestly. The initial regression variables included percentage of each city's youth population by race/ethnicity and percentage of households in which languages other than English are spoken. These variables were dropped, since youth poverty rates proved a more efficient and unambiguous correlate for teen birth rates. In 2000, 9\% of White, $19 \%$ of Asian, $26 \%$ of Hispanic, and $27 \%$ of black teens in California lived in homes with incomes below poverty guidelines.

Higher levels of health services and youth development programs targeting teens are not correlated with lower teen birth rates; in fact, they are modestly correlated with higher net teen birth rates compared to adults' and, in the case of health services, with higher absolute teen birth rates. However, this correlation is probably backwards; it more likely reflects the targeting of services toward low-income teens rather than a negative effect of services themselves. As Table 2 indicates, youth in cities with higher youth poverty rates have considerably more teen health services and youth development programs available than youth in more affluent cities.

To isolate the effect of youth services, a stepwise multiple regression analysis examines their effect on teen birth rates (both level and change) when adult birth rates, economic variables such as poverty rates, and city population size are controlled (see Table 3). One factor, the variation in adult birth rates by city, is associated with $75 \%$ of the variation in teen birth rates by city $(r=0.868)$. Adding the youth poverty variable boosts the equation's explanatory power to $88 \%$ of the teen birth rate (multiple $r=0.942$ ). Four additional variables (percent of population with a high school education, percent of Table 3population owning own home, percent of population in labor force, and level of youth development services) raise the explanatory power of the regression equation only marginally, to $91 \%$ (multiple $r=0.958$ ). 
Table 2

Services to youth, social measures, and teen and adult birth rates in California's 55 largest cities, arranged by youth poverty rate

\begin{tabular}{|l|l|l|l|l|l|l|}
\hline Percent of youth in poverty & $5-9 \%$ & $10-14 \%$ & $15-19 \%$ & $20-24 \%$ & $25-29 \%$ & $30 \%+$ \\
\hline Services (average score) & & & & & & \\
\hline Youth development & & & & & & \\
\hline Health services & 12.4 & 14.2 & 13.8 & 16.1 & 18.3 & 18.3 \\
\hline Total services & 13.1 & 16.9 & 15.4 & 16.4 & 19.3 & 19.4 \\
\hline Economic measures & 25.5 & 31.1 & 29.2 & 32.6 & 37.7 & 37.7 \\
\hline Mean youth poverty rate & & & & & & \\
\hline Median household income & $7.0 \%$ & $12.6 \%$ & $17.9 \%$ & $21.6 \%$ & $28.3 \%$ & $33.2 \%$ \\
\hline Home ownership rate & 64.669 & $\$ 52,098$ & $\$ 46,035$ & $\$ 43,060$ & $\$ 39,042$ & $\$ 34,213$ \\
\hline Labor force participation & $68.2 \%$ & $56.0 \%$ & $57.1 \%$ & $52.6 \%$ & $49.6 \%$ & $44.5 \%$ \\
\hline Educational attainment & & & $63.6 \%$ & $61.2 \%$ & $59.8 \%$ & $58.8 \%$ \\
\hline High school graduation & $88.0 \%$ & $79.4 \%$ & $70.6 \%$ & $70.1 \%$ & $68.7 \%$ & $64.2 \%$ \\
\hline Percent with BA degree & 35.6 & 28.1 & 17.4 & 21.4 & 22.5 & 16.5 \\
\hline Average birth rate/1,000 females & & & & & & \\
\hline Teen (age 15-19) & 20.6 & 38.0 & 61.9 & 64.1 & 77.6 & 76.9 \\
\hline White & 12.6 & 13.9 & 27.2 & 26.7 & 39.7 & 40.1 \\
\hline Latina & 64.7 & 77.7 & 99.5 & 108.4 & 128.1 & 116.1 \\
\hline Black & 27.1 & 42.5 & 35.5 & 60.0 & 69.4 & 59.4 \\
\hline Asian & 6.1 & 8.6 & 18.4 & 20.4 & 30.5 & 50.4 \\
\hline Adult (age 20-44) & 60.6 & 73.5 & 92.4 & 88.7 & 97.1 & 96.8 \\
\hline Teen vs. adult birth rate & 0.34 & 0.52 & 0.67 & 0.72 & 0.79 & 0.80 \\
\hline
\end{tabular}

Of the variables showing significant associations, higher adult birth rates, teen poverty rates, labor force participation, and youth development programs are associated with higher teen birth rates, while high school graduation levels are associated with lower teen birth rates. Two additional variables, percent of population with a bachelor's degree and city population size, approached statistical significance $(\mathrm{p}=0.07)$. The remaining variables did not approach significance.

It could be argued that the best measure of the factors uniquely influencing teen births is not the absolute teen birth rate, but the ratio of the teen birth rate to that of adults. This ratio, or the "net teen birth rate," also varies substantially. Teen females in Irvine are just $5.5 \%$ as likely to have babies as Irvine adults, while teens in San Bernardino are $91.4 \%$ as likely to have babies compared to local adults. The ratio variable presents methodological problems in regression, and its use in this case as the dependent variable is to remove the powerful correlate of the adult birth rate to reveal other factors meriting exploration. Just one additional variable, the proportion graduating from high school, is significantly associated with the variance in net teen birth rates across the 55 cities. Weaker associations, both positive, are found between the net teen birth rate and the teen poverty rate and the availability of youth development programs. 
Table 3

Levels and changes in teen birth rates, regressed against adult birth rates, economic variables, and services to youth, 55 California cities, 1990-2002.

\begin{tabular}{|c|c|c|c|c|}
\hline & $\begin{array}{c}\text { Weighted } \\
\text { coefficient }\end{array}$ & Error & T & Sig T \\
\hline Absolute teen birth rate, 2002 & & & & \\
\hline Adult birth rate & 0.623 & 0.024 & 12.12 & 0.000 \\
\hline Teen poverty rate & 0.322 & 0.050 & 4.26 & 0.000 \\
\hline Percent with high school diplomas & -0.281 & 0.036 & -3.89 & 0.000 \\
\hline Net teen birth rate (vs adult birth rate), 2002 & & & & \\
\hline Percent with high school diplomas & -0.494 & 0.083 & -4.69 & 0.000 \\
\hline Youth development programs & 0.287 & 1.654 & 3.48 & 0.001 \\
\hline Teen poverty rate & 0.337 & 0.119 & 2.94 & 0.005 \\
\hline Absolute change in teen birth rate, 1990-2002 & & & & \\
\hline Change in adult birth rate, 1990-2002 & 0.778 & 0.062 & 9.00 & 0.000 \\
\hline Percent with bachelor's degree & -0.314 & 0.128 & -3.94 & 0.000 \\
\hline $\begin{array}{l}\text { Net change in teen birth rate (vs. change in } \\
\text { adult birth rate), 1990-2002 }\end{array}$ & & & & \\
\hline Percent with bachelor's degree & -0.490 & 0.130 & -4.31 & $0.000^{* *}$ \\
\hline
\end{tabular}

${ }^{*} \mathrm{p}<.01 ; * * \mathrm{p}<.001$

\section{Changes in teen birth rates}

From 1990 to 2002, 51 of the 55 cities experienced declines in teen birth rates (led by a $79 \%$ decrease in Irvine), and four had increases (led by a $20 \%$ rise in Daly City). Changes in teen birth rates are most firmly linked to changes in adult birth rates, with the percentage of the city's population holding bachelor's degrees a distant second in significance. These factors explain nearly two-thirds of the variation in changes in teen birth rates over the 12-year period. No other factor approaches statistical significance.

\section{Discussion}

These findings from 55 California cities invite conclusions the opposite of those stressed by the major interest groups that dominate the United States' discussions of causal factors in teen pregnancy and motherhood. The only two factors significantly affecting the rates of birth by teenage mothers are the rates of birth by adult mothers and the percentages of youth living in poverty, which together are associated with $89 \%$ of the large variation in teen birth rates by city. Certain factors related to socioeconomic inequality, such as educational attainment, home ownership, and employment also affect teen birth rates to a much lesser degree. The influence of factors in their social environments on teen birth rates is so powerful that there appears little that services and programs could do to overcome them, barring massive program investments of the type that effectively change poorer teens' socioeconomic standing (Kirby, 2001; National Adolescent Sexuality Training Center, 2005).

Also contradicting assertions by various advocates, higher birth rates among lowerincome teens are not explained by a paucity of health and development services, In fact, lowerincome teens living in poorer cities tend to have significantly more health and development services available than teens in wealthier cities. This situation produces a modest correlation between greater availability of health services for adolescents and youth development programs and higher teen birth rates by city, both in absolute terms and in relation to adult birth rates. However, it is not likely that more youth services promote higher teen birth rates, 
but that services tend to be focused on poorer youth (whose birth rates are higher due to environmental conditions) to compensate for the fact that wealthier youth have more access to resources and private health care. If this is the case, the ranking of health and development services becomes an endogenous variable whose dependence is controlled in the regression equation by the inclusion of youth poverty and other economic variables, resulting in a nonsignificant coefficient for services. Finally, again contradicting advocates' statements, greater availability of teen health and development programs are not correlated with greater reductions in teen birth rates over the last decade, either on an absolute basis or in relation to adult birth rates.

Services and programs may have other benefits not measured by this study. One possible benefit is hinted here. Despite the fact that labor force participation tends to decline as youth poverty rates rise, labor force participation is higher in cities with stronger youth development programs, even though these cities also have higher youth poverty rates and higher teen birth rates. A reasonable hypothesis for further study is that youth development programs may not prevent births by teenage mothers, but they do have the benefit of significantly enhancing the employability of low-income young people, including young parents.

The only variables correlated with a greater decline in a city's teen birth rate are a greater decline in the city's adult birth rates and, to a lesser extent, a higher proportion of the city's population with a bachelor's degree. The latter may reflect the fact that cities whose college populations have grown the most tend to attract a greater proportion of college-attending and educated residents who are the least likely to have babies at young ages. Another reasonable hypothesis would be that expanding the opportunity to attend college would represent a significant deterrent to teenage parenthood. The low teen birth rates found in both Berkeley and Irvine owe more to their dominance by large state universities attracting education-oriented teenagers unlikely to have babies than to their levels of health services or contrasting sexuality and abstinence educational regimes.

\section{Limitations}

This study has several limitations. First, California does not tabulate abortions, making calculation of pregnancy rates, a more comprehensive measure than birth rates, impossible. National figures indicate that poorer women, including teenagers, have higher abortion rates than more affluent women, but the gap is not as pronounced as for birth rates (Ventura et al., 2004). Second, the findings apply to residents of cities with more than 100,000 people; the results may not be generalizable to those in smaller towns or rural areas. Third, ideal baseline measures, such as corresponding levels of health and development services to teens by city in the early 1990s, are not available, nor are other possible programmatic influences such as type of sexuality education program by city. Finally, ranking of services involves judgments. That the rankings were performed by groups that are advocates for providing more health, contraception, and sexuality education services to teenagers should be considered by readers.

\section{Conclusions}

Teenage birth rates vary greatly across California's 55 largest cities, and the interrelated social factors of economic status and adult birth rates account for nearly all of the variation. The provision of health services and youth development programs for teenagers is not associated with lower rates of or greater reductions in births among teens, even when other relevant factors are controlled. However, services and programs may have other benefits not measured by this study, such as improving the employability of low-income young people. These results suggest that groups that wish to reduce teenage birth rates should emphasize reducing poverty rates, promoting healthy sexual behaviors by both adults and teens in an integrated fashion, improving access to higher education for youth, and refraining from suggesting that services and programs can reduce teen birth rates in the absence of improving their socioeconomic environments. 


\section{References}

Advocates for Youth. (2005). Teen pregnancy. Retrieved November 15, 2005, from http://www.advocatesforyouth.org/teenpregnancy.htm

Alan Guttmacher Institute. (2001). Five-country study points to ways the United States could further decrease teenage pregnancy and STD rates. Press Release, November 29, 2001. Retrieved November 15, 2005, from http://www.guttmacher.org/media/nr/nr_euroteens.html

Bender, K. (2004). California: Birth rate for teens in Berkeley a state low. Oakland Tribune, September 23, 2004, p. B1.

Bureau of the Census (2005). Census of population, California, 2000. Summary Files 1, 3. Retrieved November 15, 2005, from http://www.census.gov

California Adolescent Health Collaborative (2005). Pregnancy, STI overview. Retrieved November 15, 2005, from http://www.californiateenhealth.org/pregnancy_sti_overview.asp

California Wellness Foundation (2005). Teenage pregnancy prevention. Retrieved November 15, 2005, from http://www.tcwf.org/health issues/teen pregnancy.htm/

Center for Health Statistics (2004). Birth public use file, 2002. Electronic data file available from CCHS, Department of Health Services, Sacramento, CA.

Constantine, N. A., \& Nevarez, C. R. (2002). No time for complacency: Teen births in California. Public Health Institute, Center for Research on Adolescent Health and Development, Public Health Institute.

Darroch, J. E., Frost, J. J., \& Singh, S. (2001). Teenage sexual and reproductive behavior in developed countries: Can more progress be made? New York: Alan Guttmacher Institute.

Get Real! About Teen Pregnancy. (2005). Campaign materials. Retrieved November 15, 2005, from http://www.letsgetreal.org/CampaignMaterials.htm

Get Real About Teen Pregnancy, California Adolescent Health Collaborative. (2004). Reality Check: Methodology. Retrieved November 15, 2005, from http://www.letsgetreal.org/nr_RealityCheckMethodology.htm. Reality Check--Final Data Tables. 2004. Retrieved November 15, 2005, from http://www.letsgetreal.org/pdfs/datatables.pdf

Get Real About Teen Pregnancy, California Adolescent Health Collaborative. (September 22, 2004). Teen birth rate declines, but challenges loom for California cities. 55 cities get "Reality Check." http://www.letsgetreal.org/nr_RealityCheckCities_2004.htm

Hotz, V. J. et al. (1997). The impact of teenage childbearing on the mothers and the consequences of those impacts for government. In R. A. Maynard (Ed.) (1997), Kids having kids: Economic costs and social consequences of teen pregnancy. Washington, DC: Urban Institute.

Hotz, V.J., McElroy S.W., \& Sanders, S.G. (2000). Teenage childbearing and its life cycle consequences: Exploiting a natural experiment. Los Angeles: University of California, Department of Economics.

Irvine Public Schools. (2003). Board of education policies. Retrieved November 15, 2005, from http://www.iusd.k12.ca.us/bdpolicy/default.htm

Kirby, D. (2001). Emerging answers: Research findings on programs to reduce teen pregnancy. Washington, DC: National Campaign to Prevent Teen Pregnancy, 2001.

Kirby, D. (2002). Do abstinence-only programs delay the initiation of sex among young people and reduce teen pregnancy? Washington, DC: National Campaign to Prevent Teen Pregnancy.

Lambert, L. (2005). Berkeley high: A sex ed success story. Planned Parenthood. Retrieved November 15, 2005, from http://www.plannedparenthood.org/pp2/portal/files/portal/webzine/newspoliticsactivism/fean050127-berkeley.xml

Luker, K. (1996). Dubious conceptions: The politics of teenage pregnancy. Cambridge: Harvard University Press.

Musick, J. (1993). Young, poor, and pregnant: The psychology of teenage motherhood. New Haven: Yale University Press. 
National Adolescent Sexuality Training Center. (2005). The children's aid society. Retrieved November 15, 2005, from

http://www.childrensaidsociety.org/press/releasearchive/article/1525447

National Campaign to Prevent Teen Pregnancy. (2005). What works. Retrieved November 15, 2005, from http://www.teenpregnancy.org/works/default.asp

Sexuality Information and Education Council of the United States. (2005). Retrieved November 15, 2005, from http://www.siecus.org/youth/index.html

Ventura, S. J., Abma, J. C., \& Mosher, W. D. (2004). Estimated pregnancy rates for the United States,1990-2000: An update. National Vital Statistics Report, 52:23, June 15, 2004.

Author Information

Mike Males, Ph.D.

Sociology Department

University of California, Santa Cruz, CA 95064 


\section{Appendix A}

Teen birth rates and levels of services in California's 55 largest cities, 2002, ranked by teen birth rate

\begin{tabular}{|c|c|c|c|c|c|c|}
\hline \multirow[b]{2}{*}{ City } & \multicolumn{2}{|c|}{$\begin{array}{c}\text { Births per } \\
1,000 \text { females* }\end{array}$} & \multicolumn{3}{|c|}{$\begin{array}{l}\text { Youth services } \\
\text { rating** }\end{array}$} & \multirow{2}{*}{\begin{tabular}{|c|} 
Youth In \\
Poverty (\%) \\
\end{tabular}} \\
\hline & Teen & Adult & Health & Development & Total & \\
\hline Bakersfield & 23.9 & 134.6 & 16 & 15 & 31 & 24.4 \\
\hline San Bernardino & 21.8 & 116.3 & 16 & 20 & 36 & 36.2 \\
\hline Sacramento & 20.3 & 131.0 & 23 & 23 & 46 & 29.5 \\
\hline Stockton & 18.8 & 118.1 & 18 & 17 & 35 & 32.8 \\
\hline Inglewood & 18.5 & 100.3 & 12 & 12 & 24 & 30.1 \\
\hline Fresno & 18.5 & 98.6 & 23 & 22 & 45 & 36.5 \\
\hline Oxnard & 18.5 & 98.8 & 15 & 20 & 35 & 18.4 \\
\hline Salinas & 17.2 & 93.0 & 17 & 13 & 30 & 20.1 \\
\hline Modesto & 17.2 & 111.6 & 15 & 19 & 34 & 21.9 \\
\hline Santa Ana & 16.6 & 96.4 & 20 & 15 & 35 & 24.1 \\
\hline Fontana & 16.2 & 126.0 & 10 & 09 & 19 & 18.2 \\
\hline El Monte & 15.7 & 95.2 & 14 & 14 & 28 & 33.9 \\
\hline Pomona & 15.0 & 90.2 & 12 & 14 & 26 & 27.4 \\
\hline Ontario & 14.9 & 87.4 & 12 & 12 & 24 & 19.1 \\
\hline Riverside & 14.8 & 108.6 & 17 & 20 & 37 & 18.9 \\
\hline Escondido & 14.5 & 93.4 & 13 & 19 & 32 & 17.9 \\
\hline Oceanside & 14.4 & 100.5 & 14 & 18 & 32 & 16.2 \\
\hline Los Angeles & 12.8 & 72.8 & 24 & 26 & 50 & 30.3 \\
\hline Oakland & 12.6 & 70.3 & 20 & 21 & 41 & 27.9 \\
\hline Lancaster & 12.6 & 85.4 & 14 & 18 & 32 & 21.9 \\
\hline Hayward & 12.1 & 90.8 & 14 & 19 & 33 & 11.7 \\
\hline Anaheim & 12.1 & 86.3 & 18 & 15 & 33 & 18.9 \\
\hline Santa Rosa & 11.9 & 87.4 & 18 & 19 & 37 & 9.5 \\
\hline Palmdale & 11.8 & 88.9 & 8 & 15 & 23 & 20.1 \\
\hline Long Beach & 11.7 & 76.2 & 21 & 25 & 46 & 32.7 \\
\hline Pasadena & 10.7 & 72.4 & 17 & 17 & 34 & 21.3 \\
\hline Chula Vista & 10.4 & 102.0 & 14 & 21 & 35 & 13.0 \\
\hline Corona & 10.2 & 107.5 & 12 & 13 & 25 & 10.1 \\
\hline Moreno Valley & 9.7 & 83.6 & 14 & 10 & 24 & 18.1 \\
\hline Norwalk & 9.6 & 83.0 & 12 & 10 & 22 & 14.8 \\
\hline San Diego & 9.1 & 64.0 & 24 & 25 & 49 & 20.0 \\
\hline Garden Grove & 9.1 & 76.9 & 14 & 15 & 29 & 17.1 \\
\hline Vallejo & 8.8 & 80.4 & 13 & 17 & 30 & 12.2 \\
\hline Fullerton & 8.4 & 65.0 & 11 & 22 & 33 & 13.6 \\
\hline Costa Mesa & 8.4 & 62.6 & 11 & 16 & 27 & 16.0 \\
\hline Orange & 8.4 & 75.5 & 13 & 11 & 24 & 12.5 \\
\hline San Jose & 8.4 & 78.3 & 23 & 19 & 42 & 10.3 \\
\hline Downey & 7.9 & 72.9 & 10 & 12 & 22 & 14.4 \\
\hline Concord & 7.2 & 70.6 & 14 & 13 & 27 & 9.0 \\
\hline San Buenaventura & 7.1 & 68.2 & 15 & 13 & 28 & 12.2 \\
\hline Sunnyvale & 6.6 & 69.7 & 11 & 12 & 23 & 5.5 \\
\hline West Covina & 6.5 & 72.3 & 11 & 15 & 26 & 11.1 \\
\hline
\end{tabular}




\begin{tabular}{|l|r|r|r|c|r|r|}
\hline & \multicolumn{1}{|c|}{$\begin{array}{c}\text { Births per } \\
\text { 1,000 females* }\end{array}$} & \multicolumn{3}{c|}{$\begin{array}{c}\text { Youth services } \\
\text { rating** }\end{array}$} & Youth In \\
\hline \multicolumn{1}{|c|}{ City } & Teen & \multicolumn{1}{c|}{ Adult } & Health & Development & Total & Poverty (\%) \\
\hline San Francisco & 5.9 & 42.4 & 23 & 26 & 49 & 13.5 \\
\hline Daly City & 5.2 & 58.5 & 11 & 11 & 22 & 7.4 \\
\hline Torrance & 4.7 & 76.9 & 14 & 12 & 26 & 7.0 \\
\hline Simi Valley & 4.5 & 74.8 & 12 & 13 & 25 & 6.2 \\
\hline Huntiington Beach & 4.2 & 57.3 & 14 & 14 & 28 & 8.2 \\
\hline Fremont & 3.6 & 76.5 & 14 & 13 & 27 & 5.9 \\
\hline Berkeley & 3.5 & 35.8 & 14 & 22 & 36 & 13.4 \\
\hline Burbank & 3.3 & 55.0 & 14 & 17 & 31 & 13.3 \\
\hline Rancho Cucamonga & 2.9 & 39.4 & 11 & 10 & 21 & 7.6 \\
\hline Santa Clarita & 2.7 & 60.7 & 10 & 12 & 22 & 6.7 \\
\hline Glendale & 2.4 & 51.8 & 14 & 11 & 25 & 20.7 \\
\hline Thousand Oaks & 1.7 & 46.4 & 11 & 14 & 25 & 5.2 \\
\hline Irvine & 0.8 & 60.7 & 9 & 14 & 23 & 6.1 \\
\hline Mean 55 cities & 10.7 & 81.8 & 14.8 & 16.2 & 31.0 & 17.3 \\
\hline
\end{tabular}

*Births per 1,000 females ages 15-19 and ages 20-44.

**Rankings by Get Real About Teen Pregnancy, California Adolescent Health Collaborative (2004). 